\title{
Elevated 1-h post-challenge plasma glucose levels in subjects with normal glucose tolerance or impaired glucose tolerance are associated with whole blood viscosity
}

\author{
Maria Adelaide Marini ${ }^{1}$ Teresa Vanessa Fiorentino ${ }^{2}$. Francesco Andreozzi ${ }^{2}$. \\ Gaia Chiara Mannino ${ }^{2} \cdot$ Maria Perticone $^{2} \cdot$ Angela Sciacqua $^{2} \cdot$ Francesco Perticone $^{2}$. \\ Giorgio Sesti ${ }^{2}$
}

Received: 27 February 2017/ Accepted: 18 May 2017

(C) Springer-Verlag Italia 2017

\begin{abstract}
Aim It has been suggested that glucose levels $\geq 155 \mathrm{mg} / \mathrm{dl}$ at 1-h during an oral glucose tolerance test (OGTT) may predict development of type 2 diabetes and cardiovascular events among adults with normal glucose tolerance (NGT $1 \mathrm{~h}$-high). Studies showed a link between increased blood viscosity and type 2 diabetes. However, whether blood viscosity is associated with dysglycemic conditions such as NGT 1 h-high, impaired glucose tolerance (IGT) or impaired fasting glucose (IFG) is unsettled.

Methods 1723 non-diabetic adults underwent biochemical evaluation and OGTT. A validated formula based on hematocrit and total plasma proteins was employed to estimate whole blood viscosity. Subjects were categorized into NGT with $1 \mathrm{~h}$ glucose $<155 \mathrm{mg} / \mathrm{dL}$ (NGT-1 h-low), NGT-1 h-high, IFG and/or IGT.

Results Hematocrit and blood viscosity values appeared significantly higher in individuals with NGT 1 h-high, IFG and/or IGT as compared to NGT 1 h-low subjects. Blood viscosity was significantly correlated with age, waist circumference, blood pressure, HbA1c, fasting, 1- and 2-h post-challenge insulin levels, total cholesterol and low-
\end{abstract}

Managed by Antonio Secchi.

Maria Adelaide Marini and Teresa Vanessa Fiorentino have contributed equally to this work.

Giorgio Sesti

sesti@unicz.it

1 Department of Systems Medicine, University of Rome Tor Vergata, 00133 Rome, Italy

2 Department of Medical and Surgical Sciences, University Magna-Græcia of Catanzaro, Viale Europa, 88100 Catanzaro, Italy density lipoprotein, triglycerides, fibrinogen, white blood cell, and inversely correlated with high-density lipoprotein and insulin sensitivity. Of the four glycemic parameters, 1-h post-challenge glucose showed the strongest correlation with blood viscosity $(\beta=0.158, P<0.0001)$ in a multivariate regression analysis model including several atherosclerosis risk factors.

Conclusions Our results demonstrate a positive relationship between blood viscosity and 1-h post-challenge plasma glucose. They also suggest that a subgroup of NGT individuals with 1 -h post-challenge plasma $>155 \mathrm{mg} / \mathrm{dl}$ have increased blood viscosity comparable to that observed in subjects with IFG and/or IGT.

Keywords $1 \mathrm{~h}$ post-load hyperglycemia - Blood viscosity Hematocrit · Impaired glucose tolerance

\section{Introduction}

Blood viscosity is due to the frictional interactions between major blood components, i.e. plasma, plasma proteins and red blood cells, and it is a measure of the intrinsic resistance of blood to flow. Increased blood viscosity has been reported to be related with major cardiovascular risk factors including hyperlipidemia, diabetes mellitus, hypertension, cigarette smoking, metabolic syndrome, obesity, hyperfibrinogenemia [1-6]. In addition, whole blood viscosity has been found to be associated with left ventricular hypertrophy, atherosclerosis, vascular stiffness, and non-alcoholic fatty liver, as well as to predict cardiovascular diseases [7-15]. Given the negative association between blood viscosity and flow, an elevated blood viscosity may be involved in the pathogenesis of insulin resistance and type 2 diabetes mellitus, 
as it may result in reduced glucose and insulin delivery to metabolically active tissues [16]. Indeed, several crosssectional studies have shown a connection between increased blood viscosity, impaired insulin sensitivity, and type 2 diabetes [16-20]. More importantly, longitudinal studies have demonstrated that hematocrit, a crucial parameter of blood viscosity, and blood viscosity itself are associated with incident type 2 diabetes [21-25]. These evidences suggest that elevated blood viscosity may occur early in the natural history of type 2 diabetes, but only limited data are available, since the studies carried out on subjects with normal glucose tolerance (NGT) or impaired glucose homeostasis were of small size or employed suboptimal definitions of dysglycemic states such as impaired glucose tolerance (IGT) $[6,26,27]$. Evidence has accrued suggesting that subjects with a 1-h plasma glucose concentration during an oral glucose tolerance test $($ OGTT) $>155 \mathrm{mg} / \mathrm{dl}(8.6 \mathrm{mmol} / \mathrm{l})$ are at increased risk of type 2 diabetes among those who have NGT [28-31]. Remarkably, subjects with 1-h postchallenge plasma glucose $>155 \mathrm{mg} / \mathrm{dl}$ are characterized by a cluster of cardio-metabolic abnormalities such as insulin resistance [32], pro-atherogenic lipid profile [33], hepatic steatosis [34], carotid atherosclerosis [35], vascular stiffness [36], and left ventricular hypertrophy [37], and cardiac autonomic imbalance [38] which in turn have been inked to increased blood viscosity [1, 3, 7-11]. The degree to which 1-h post-load plasma glucose $>155 \mathrm{mg} / \mathrm{dl}$ is associated with blood viscosity remains unsettled. The objective of this study, therefore, was to evaluate whether elevated estimated whole blood viscosity is cross-sectionally linked with dysglycemic conditions including with 1 -h post-challenge plasma glucose $>155 \mathrm{mg} / \mathrm{dl}$ and IGT in a cohort of well-characterized nondiabetic individuals.

\section{Methods}

We analyzed 1723 individuals consecutively recruited at the Department of Systems Medicine of the University of Rome-Tor Vergata and at the Department of Medical and Surgical Sciences of the University "Magna Graecia" of Catanzaro as previously described [30, 32-38].

Anthropometrical parameters of study participants including BMI, waist circumference, and blood pressure, and biochemical data were collected after an over-night fasting. A $75 \mathrm{~g}$ OGTT was carried out with $0,30,60$, and 120 min sampling for plasma glucose and insulin. The study was approved by the local ethics committee (Comitato Etico Azienda Ospedaliera "Mater Domini"). Every subject gave written informed consent in accordance with principles of the Declaration of Helsinki.

\section{Analytical determinations}

Hemoglobin, hematocrit, and white blood cell count were measured using an automated particle counter (Siemens Healthcare Diagnostics ADVIA ${ }^{\circledR} 120 / 2120$ Haematology System, Milan, Italy). Glucose, triglycerides, total and high density lipoprotein (HDL) cholesterol levels were assessed by enzymatic methods (Roche, Basel, Switzerland). HbA1c was measured with high performance liquid chromatography using a national glycohemoglobin standardization program (NGSP) certified automated analyzer (Adams HA$8160 \mathrm{HbA1C}$ analyzer, Menarini, Italy). Fibrinogen was determined by an automated nephelometric technology using the BNTMII System analyzer (Siemens Healthcare, Italy). Plasma insulin levels were assessed with a chemiluminescence-based assay (Immulite ${ }^{\circledR}$, Siemens Healthcare $\mathrm{GmbH}$, Erlangen, Germany).

\section{Calculations}

Study participants were categorized in accordance with their glucose tolerance status as having NGT when their fasting plasma glucose and 2-h post-challenge levels were $<100 \mathrm{mg} / \mathrm{dl}$ and $<140 \mathrm{mg} / \mathrm{dl}$, respectively, isolated impaired fasting glucose (IFG) when fasting plasma glucose was $100-125 \mathrm{mg} / \mathrm{dl}$ and $2 \mathrm{~h}$ post-load $<140 \mathrm{mg} / \mathrm{dl}$, IGT when fasting plasma glucose was $<100 \mathrm{mg} / \mathrm{dl}$ and $2 \mathrm{~h}$ post-load was 140-199 mg/dl and combination of IFG and IGT (combo IFG + IGT) when fasting plasma glucose was $100-125 \mathrm{mg} / \mathrm{dl}$ and $2-\mathrm{h}$ post-load was $140-199 \mathrm{mg} / \mathrm{dl}$. Individuals classified as NGT were subsequently divided into two groups (NGT $1 \mathrm{~h}$-low and NGT 1 h-high) based upon their 1-h plasma glucose concentration, below or above $155 \mathrm{mg} / \mathrm{dl}$, respectively.

Whole blood viscosity at $208 \mathrm{~s}^{-1}$ of shear rate was calculated by a previously validated equation that takes into account haematocrit and plasma proteins [39]: Whole blood viscosity $=[0.12 \times h]+[0.17 \times(p-2.07)]$, where $h$ is haematocrit (\%) and $p$ is plasma proteins levels ( $\mathrm{g} / \mathrm{dl})$.

The Matsuda index of insulin sensitivity was calculated as follows: 10.000 /square root of [FPG $\times$ fasting insulin] $\times$ [mean glucose $\times$ mean insulin during OGTT] [40].

\section{Statistical analysis}

Given their skewed distribution, triglycerides, fasting, 1-, and 2-h insulin were natural $\log$ transformed for statistical analyses. Continuous data are expressed as mean \pm SD. $\chi^{2}$ test was used to compare categorical variables. We used a general linear model with adjustment for age to test pairwise differences in anthropometric, metabolic, and hematological parameters among glucose tolerance groups. 
We evaluated pearson correlation coefficient to test the correlation between continuous variables. A multiple linear regression analysis was performed to assess the relationships between variables and their independent contribution to whole blood viscosity. The multicollinearity among variables in the performed regression analyses was excluded by the fact that the variance inflection factor (VIF) was less than 6 . We considered statistically significant a twosided $P$ value $<0.05$. All analyses were carried out using the statistical package SPSS 22.0 for Windows (SPSS, $\mathrm{IBM}^{\circledR}$, Chicago, IL).

\section{Results}

\section{Cardio-metabolic characteristics}

Anthropometric and metabolic data of the study cohort, distributed according to their glucose tolerance are reported in Table 1. A total of 1723 subjects were evaluated, of whom 1017 (59.0\%) had NGT, 240 (13.9\%) had isolated IGT, 245 (14.2\%) isolated IFG and 221 (12.8\%) had both IFG and IGT (combo IFG + IGT). NGT subjects were subclassified into two groups using a 1-h post-challenge plasma glucose cutoff point of $155 \mathrm{mg} / \mathrm{dl}$ during OGTT: 757 subjects had 1-h post-challenge plasma glucose $<155 \mathrm{mg} / \mathrm{dl}$ (NGT $1 \mathrm{~h}$-low) and 260 individuals had 1-h post-challenge plasma glucose $\geq 155 \mathrm{mg} / \mathrm{dl}$ (NGT $1 \mathrm{~h}$ high). Gender, and age distributions were unevenly scattered among the five groups: NGT 1 h-high, isolated IFG, isolated IGT and combo IFG + IGT harbored more men than women, while subjects with NGT 1 h-low were younger as compared with subjects of other glucose tolerance groups (Table 1). Since these two parameters are associated with hemorheological features, all subsequent analyses were adjusted for age, and gender.

By design, subjects with NGT $1 \mathrm{~h}$-high, isolated IFG, isolated IGT and combo IFG + IGT exhibited higher levels of 1- and 2-h post-challenge glucose, and $\mathrm{HbAlc}$ (Table 1). Subjects with isolated IFG, isolated IGT and combo IFG + IGT were less likely to be smokers as compared with NGT 1 h-high, and NGT 1 h-low groups. NGT 1 h-high, isolated IGT and combo IFG + IGT groups presented significantly higher values of BMI, waist circumference, triglycerides, fasting glucose, fasting, 1- and 2-h post-challenge insulin levels as compared with the NGT 1 h-low group, even after adjustment for age, and gender. Additionally, NGT 1 h-high, isolated IGT and combo IFG + IGT individuals exhibited lower values of HDL cholesterol and Matsuda index of insulin sensitivity (Table 1). Subjects with isolated IFG displayed higher levels of triglycerides, fasting glucose, fasting, 1- and 2-h post-load insulin and lower values of
Matsuda index of insulin sensitivity in comparison to NGT 1 h-low individuals (Table 1).

\section{Hemorheological characteristics}

Hemorheological parameters of the three study groups are shown in Table 2 and Fig. 1. After adjusting for age, and gender, NGT $1 \mathrm{~h}$-high, isolated IFG, isolated IGT and combo IFG + IGT groups exhibited a significant increase in values of hematocrit, white blood cell count, and whole blood viscosity while no significant differences in total protein and hemoglobin concentrations were detected.

Univariate correlations between blood viscosity and anthropometric and metabolic features in the study cohort are presented in Table 3. Whole blood viscosity was significantly associated with waist circumference, with notably weaker correlation with BMI. In addition, whole blood viscosity was significantly and positively correlated with age, systolic and diastolic blood pressure, total and LDL cholesterol, triglycerides, fibrinogen, white blood cell count, HbA1c, fasting, 1- and 2-h post-challenge plasma insulin levels, and inversely correlated with HDL cholesterol and Matsuda index of insulin sensitivity (Table 3). Importantly we observed that 1 -h post-load plasma glucose was more strongly correlated with whole blood viscosity in comparison to the other measures of glucose homeostasis, i.e. HbA1c, fasting and 2-h post-challenge plasma glucose levels.

Next, all variables that were significantly correlated with whole blood viscosity were included in a model of multivariable regression analysis to estimate their independent contribution to whole blood viscosity (Table 4). Comparison of standardized coefficients allowed the determination of the relative strength of each trait association with whole blood viscosity (listed from strongest to weakest): 1-h postchallenge glucose $(\beta=0.158, P<0.0001)$, white blood cell count $(\beta=0.137, P<0.0001)$, diastolic blood pressure $(\beta=0.116, P<0.0001)$, triglycerides $(\beta=0.099$, $P=0.002), \quad 2$-h post-challenge glucose $(\beta=0.093$, $P=0.01)$, fibrinogen $(\beta=0.090, \quad P<0.0001)$, age ( $\beta=0.075, P=0.007)$, HDL cholesterol $(\beta=-0.078$, $P=0.01)$, systolic blood pressure $(\beta=0.069, P=0.03)$, waist circumference $(\beta=0.058, P=0.03)$, and HbA1c ( $\beta=0.035, P=0.004$ ) (Table 4$)$. These factors explained $21.4 \%$ of the variance of whole blood viscosity.

Finally, to estimate the independent contribution of whole blood viscosity to 1 -h post-load glucose we carried out a multivariable regression analysis in a model including variables affecting 1-h post-load glucose (Table 5). Comparison of standardized coefficients allowed the determination of the relative strength of each trait's association with 1-h post-load glucose (listed from strongest to weakest): Matsuda index of insulin sensitivity $(\beta=-0.433$, 


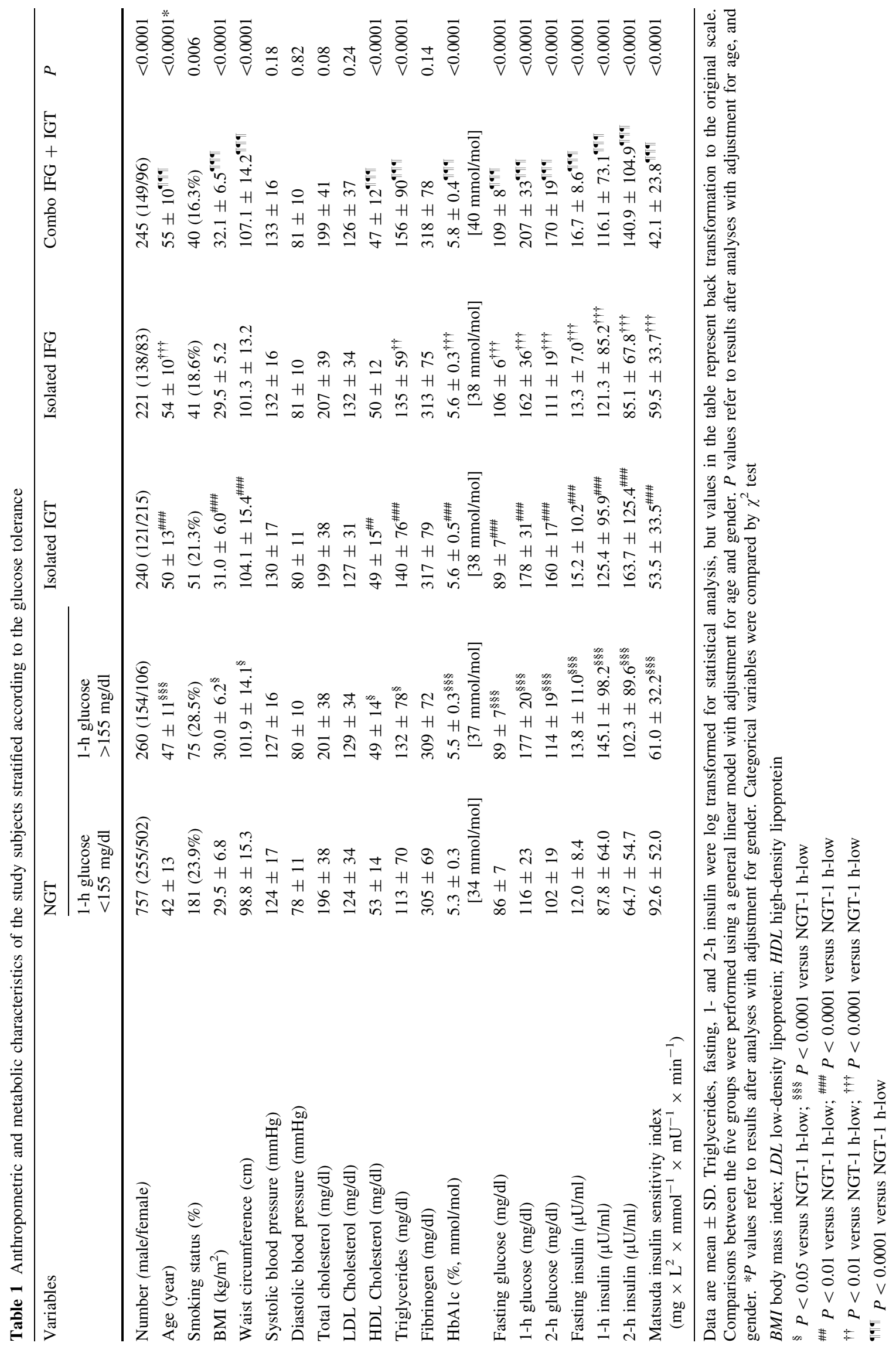


Table 2 Hemorheological characteristics of the study subjects stratified according to the glucose tolerance

\begin{tabular}{|c|c|c|c|c|c|c|}
\hline \multirow[t]{2}{*}{ Variables } & \multicolumn{2}{|l|}{ NGT } & \multirow[t]{2}{*}{ Isolated IGT } & \multirow[t]{2}{*}{ Isolated IFG } & \multirow{2}{*}{$\begin{array}{l}\text { Combo IFG + } \\
\text { IGT }\end{array}$} & \multirow[t]{2}{*}{$P$} \\
\hline & $\begin{array}{l}\text { 1-h glucose }<155 \mathrm{mg} / \\
\text { dl }\end{array}$ & $\begin{array}{l}\text { 1-h glucose }>155 \mathrm{mg} / \\
\mathrm{dl}\end{array}$ & & & & \\
\hline $\begin{array}{l}\text { White blood cell count } \\
\left(\times 10^{9} / 1\right)\end{array}$ & $6830 \pm 1897$ & $6923 \pm 1870^{\S}$ & $7180 \pm 1975^{\# \# \# ~}$ & $6937 \pm 1738^{\dagger}$ & $7014 \pm 1878^{\text {ศा }}$ & 0.003 \\
\hline Hematocrit (\%) & $40.7 \pm 4.2$ & $42.8 \pm 4.3^{\S \S}$ & $42.3 \pm 4.2^{\#}$ & $42.9 \pm 3.5^{\dagger}$ & $42.7 \pm 4.4^{\bullet}$ & 0.04 \\
\hline Hemoglobin (g/dl) & $13.5 \pm 1.5$ & $14.2 \pm 1.5$ & $14.0 \pm 1.5$ & $14.4 \pm 1.2$ & $14.2 \pm 1.5$ & 0.11 \\
\hline Total protein $(\mathrm{g} / \mathrm{l})$ & $7.22 \pm 0.46$ & $7.25 \pm 0.47$ & $7.23 \pm 0.50$ & $7.30 \pm 0.47$ & $7.29 \pm 0.49$ & 0.07 \\
\hline Whole blood viscosity (cP) & $5.77 \pm 0.52$ & $6.01 \pm 0.54^{\S \S}$ & $5.95 \pm 0.53^{\#}$ & $6.04 \pm 0.43^{\dagger \dagger}$ & $6.02 \pm 0.53^{\curvearrowleft}$ & 0.02 \\
\hline
\end{tabular}

Data are mean \pm SD. Comparisons between the five groups were performed using a general linear model with adjustment for age and gender.

$P$ values refer to results after analyses with adjustment for age, and gender

$\S P<0.05$ versus NGT-1 h-low; $\$$ \& $<0.01$ versus NGT-1 h-low

${ }^{\#} P<0.05$ versus NGT-1 h-low; ${ }^{\# \# \# ~} P<0.0001$ versus NGT-1 h-low

${ }^{\dagger} P<0.05$ versus NGT-1 h-low; ${ }^{\dagger \dagger} P<0.01$ versus NGT-1 h-low

- $P<0.05$ versus NGT-1 h-low; $P<0.01$ versus NGT-1 h-low

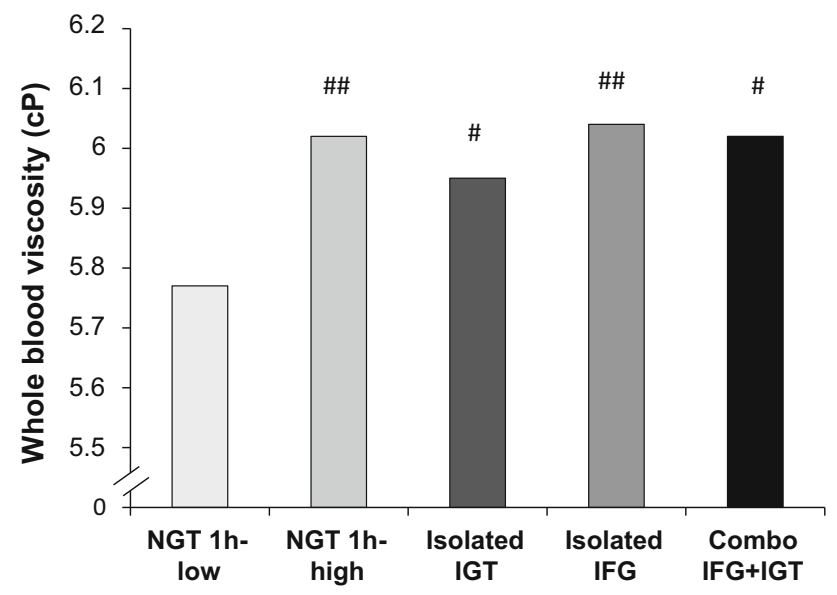

Fig. 1 Whole blood viscosity of subjects with NGT 1 h-low, NGT $1 \mathrm{~h}$-high, isolated IGT, isolated IGT and combined IFG and IGT (Combo IFG + IGT). ${ }^{\#} P<0.05$ versus NGT-1 h-low, ${ }^{\#} P<0.01$ versus NGT-1 h-low

$P<0.0001)$, age $(\beta=0.312, P<0.0001)$, gender (male) ( $\beta=0.187, \quad P<0.0001), \quad$ whole blood viscosity $(\beta=0.056, \quad P=0.03)$, and white blood cell count $(\beta=0.049, P=0.04)$ (Table 5). These factors explained $36.6 \%$ of the variance of 1 -h post-load glucose.

\section{Discussion}

In this paper we report, for the first time, a significant correlation between whole blood viscosity and NGT $1 \mathrm{~h}$ high and IGT and/or IFG, dysglycemic conditions known to increase the risk for cardiovascular diseases and type 2 diabetes [28-30]. Notably, our data suggest that, even within the normal glucose tolerance category, individuals having 1-h post-challenge plasma glucose $>155 \mathrm{mg} / \mathrm{dl}$ exhibit an increase in whole blood viscosity comparable with that observed in subjects with IGT. Significant associations of selected hemorheological parameters, mainly hematocrit, with future type 2 diabetes have been observed in previous clinical studies [21-25]. Elevated blood viscosity has been also observed in subjects with high-normal fasting glucose and IFG [6, 27]. However, these studies were carried out in small groups of individuals without performing OGTT, thus the contribution of post-load plasma glucose levels to whole blood viscosity has been overlooked. The findings of the current study extend the observations in populations with an increased risk for type 2 diabetes in several important ways. First, we evaluated the relationship of hemorheological parameters with glucose intolerance in a large cohort (1723) of nondiabetic individuals. The associations of hemorheological parameters with NGT $1 \mathrm{~h}$-high, IFG and IGT in this study were consistent, and a strong association of 1- and 2-h postchallenge glucose levels with whole blood viscosity was observed even after adjustment for multiple covariates. Remarkably, we found that 1-h post-load plasma glucose value were positively correlated with whole blood viscosity, this correlation was stronger than those observed for the other glucose homoeostasis measures, i.e. HbA1c, fasting glucose, and 2-h post-challenge glucose levels, and independent of the major atherosclerosis risk factors. It is noteworthy that among the 706 individuals with altered glucose tolerance, $593(84 \%)$ had also 1-h post-challenge plasma glucose $>155 \mathrm{mg} / \mathrm{dl}$ thus indicating that 1 -h plasma glucose was a strong contributor to elevated whole blood viscosity also in subjects with impaired glucose tolerance 
Table 3 Univariate correlations between whole blood viscosity and anthropometric and metabolic variables

\begin{tabular}{|c|c|c|}
\hline & $\begin{array}{l}\text { Whole blood viscosity } \\
r\end{array}$ & $P$ \\
\hline Age (years) & 0.14 & $<0.0001$ \\
\hline BMI $\left(\mathrm{kg} / \mathrm{m}^{2}\right)$ & 0.03 & 0.11 \\
\hline Waist circumference $(\mathrm{cm})$ & 0.16 & $<0.0001$ \\
\hline Systolic blood pressure $(\mathrm{mmHg})$ & 0.24 & $<0.0001$ \\
\hline Diastolic blood pressure $(\mathrm{mmHg})$ & 0.26 & $<0.0001$ \\
\hline Total cholesterol (mg/dl) & 0.14 & $<0.0001$ \\
\hline LDL cholesterol (mg/dl) & 0.16 & $<0.0001$ \\
\hline HDL cholesterol (mg/dl) & -0.18 & $<0.0001$ \\
\hline Triglycerides (mg/dl) & 0.26 & $<0.0001$ \\
\hline Fibrinogen $(\mathrm{mg} / \mathrm{dl})$ & 0.09 & 0.001 \\
\hline White blood cell count $\left(\times 10^{9} / 1\right)$ & 0.17 & $<0.0001$ \\
\hline $\mathrm{HbA} 1 \mathrm{c}(\%, \mathrm{mmol} / \mathrm{mol})$ & 0.05 & 0.03 \\
\hline Fasting glucose $(\mathrm{mg} / \mathrm{dl})$ & 0.15 & $<0.0001$ \\
\hline 1-h glucose $(\mathrm{mg} / \mathrm{dl})$ & 0.21 & $<0.0001$ \\
\hline 2-h glucose $(\mathrm{mg} / \mathrm{dl})$ & 0.11 & $<0.0001$ \\
\hline Fasting insulin $(\mu \mathrm{U} / \mathrm{ml})$ & 0.13 & $<0.0001$ \\
\hline 1 -h insulin $(\mu \mathrm{U} / \mathrm{ml})$ & 0.17 & $<0.0001$ \\
\hline 2-h insulin $(\mu \mathrm{U} / \mathrm{ml})$ & 0.14 & $<0.0001$ \\
\hline Matsuda insulin sensitivity index $\left(\mathrm{mg} \times \mathrm{L}^{2} \times \mathrm{mmol}^{-1} \times \mathrm{mU}^{-1} \times \min ^{-1}\right)$ & -0.19 & $<0.0001$ \\
\hline
\end{tabular}

$B M I$ body mass index, $L D L$ low-density lipoprotein, $H D L$ high-density lipoprotein

Table 4 Multiple regression analysis with whole blood viscosity as the dependent variable

\begin{tabular}{|c|c|c|}
\hline & $\begin{array}{l}\text { Whole blood viscosity } \\
\beta( \pm \text { SE) }\end{array}$ & $P$ \\
\hline Age (years) & $0.075( \pm 0.001)$ & 0.007 \\
\hline Waist circumference $(\mathrm{cm})$ & $0.058( \pm 0.001)$ & 0.03 \\
\hline Systolic blood pressure $(\mathrm{mmHg})$ & $0.069( \pm 0.001)$ & 0.03 \\
\hline Diastolic blood pressure $(\mathrm{mmHg})$ & $0.116( \pm 0.001)$ & $<0.0001$ \\
\hline Total cholesterol (mg/dl) & $0.008( \pm 0.001)$ & 0.87 \\
\hline LDL cholesterol (mg/dl) & $0.078( \pm 0.001)$ & 0.09 \\
\hline HDL cholesterol (mg/dl) & $-0.071( \pm 0.001)$ & 0.01 \\
\hline Triglycerides (mg/dl) & $0.099( \pm 0.034)$ & 0.002 \\
\hline Fibrinogen (mg/dl) & $0.090( \pm 0.001)$ & $<0.0001$ \\
\hline White blood cell count $\left(\times 10^{9} / 1\right)$ & $0.137( \pm 0.001)$ & $<0.0001$ \\
\hline $\mathrm{HbA} 1 \mathrm{c}(\%, \mathrm{mmol} / \mathrm{mol})$ & $0.035( \pm 0.001)$ & 0.004 \\
\hline Fasting glucose $(\mathrm{mg} / \mathrm{dl})$ & $0.035( \pm 0.002)$ & 0.22 \\
\hline 1-h Glucose (mg/dl) & $0.158( \pm 0.002)$ & $<0.0001$ \\
\hline 2-h Glucose (mg/dl) & $0.093( \pm 0.001)$ & 0.01 \\
\hline Fasting insulin $(\mu \mathrm{U} / \mathrm{ml})$ & $0.004( \pm 0.034)$ & 0.90 \\
\hline 1-h Insulin $(\mu \mathrm{U} / \mathrm{ml})$ & $0.002( \pm 0.033)$ & 0.90 \\
\hline 2-h Insulin $(\mu \mathrm{U} / \mathrm{ml})$ & $0.047( \pm 0.028)$ & 0.22 \\
\hline Matsuda insulin sensitivity index $\left(\mathrm{mg} \times \mathrm{L}^{2} \times \mathrm{mmol}^{-1} \times \mathrm{mU}^{-1} \times \min ^{-1}\right)$ & $0.036( \pm 0.001)$ & 0.43 \\
\hline
\end{tabular}

$L D L$ low-density lipoprotein, $H D L$ high-density lipoprotein 
Table 5 Multiple regression analysis with 1-h post-load plasma glucose levels as the dependent variable

\begin{tabular}{|c|c|c|}
\hline & $\begin{array}{l}\text { 1-h post-load plasma glucose levels } \\
\beta( \pm \mathrm{SE})\end{array}$ & $P$ \\
\hline Age (years) & $0.312( \pm 0.088)$ & $<0.0001$ \\
\hline Gender (male) & $0.187( \pm 2.859)$ & $<0.0001$ \\
\hline $\mathrm{BMI}\left(\mathrm{kg} / \mathrm{m}^{2}\right)$ & $0.016( \pm 0.338)$ & 0.72 \\
\hline Waist circumference $(\mathrm{cm})$ & $0.023( \pm 0.147)$ & 0.62 \\
\hline Systolic blood pressure $(\mathrm{mmHg})$ & $0.035( \pm 0.087)$ & 0.25 \\
\hline Diastolic blood pressure $(\mathrm{mmHg})$ & $0.048( \pm 0.132)$ & 0.11 \\
\hline Total cholesterol (mg/dl) & $0.034( \pm 0.032)$ & 0.18 \\
\hline HDL cholesterol $(\mathrm{mg} / \mathrm{dl})$ & $-0.025( \pm 0.100)$ & 0.39 \\
\hline Triglycerides (mg/dl) & $0.037( \pm 2.938)$ & 0.22 \\
\hline Fibrinogen (mg/dl) & $0.008( \pm 0.016)$ & 0.74 \\
\hline White blood cell count $\left(\times 10^{9} / 1\right)$ & $0.049( \pm 0.001)$ & 0.04 \\
\hline Whole blood viscosity & $0.056( \pm 0.272)$ & 0.03 \\
\hline Matsuda insulin sensitivity index $\left(\mathrm{mg} \times \mathrm{L}^{2} \times \mathrm{mmol}^{-1} \times \mathrm{mU}^{-1} \times \min ^{-1}\right)$ & $-0.433( \pm 0.029)$ & $<0.0001$ \\
\hline
\end{tabular}

$B M I$ body mass index, $H D L$ high-density lipoprotein

conditions. On the other hand, in a multivariate regression analysis model including multiple factors influencing glucose tolerance, whole blood viscosity was an independent contributor to 1-h post-load plasma glucose indicating that hemorheological abnormalities may affect glucose homeostasis. The mechanism underlying the observed relationship between elevated 1-h post-load plasma glucose levels and elevated whole blood viscosity is undefined. An impaired insulin sensitivity could be one possible explanation since prior studies have repeatedly reported that individuals with NGT 1 h-high have impaired insulinstimulated glucose disposal [32, 41]. Accordingly, we observed a decreased insulin sensitivity in NGT subjects with 1 -h post-challenge plasma glucose $>155 \mathrm{mg} / \mathrm{dl}$ in comparison to NGT individuals with 1-h post-challenge plasma $<155 \mathrm{mg} / \mathrm{dl}$. Several mechanisms may explain the association of hematocrit, the foremost determinant of whole blood viscosity, or viscosity itself with insulin resistance. Elevated blood viscosity is associated with decreased flow. A lower blood flow, in turn, counteracts the transport of glucose to skeletal muscle [17]. This leads to compensatory vasodilatation and increase in blood pressure in an attempt to rise blood flow. The reduced glucose transport in the tissues causes an increase in the circulating glucose levels which promotes insulin secretion. Alternatively, hyperinsulinemia due to insulin resistance may induce sympathetic neural activation, promote arterial vasodilation and venous vasoconstriction, with consequent fluid extravasation which in turn would lead to hemoconcentration and increased blood viscosity [18, 19].

Furthermore, chronic subclinical inflammation may represent a common mechanistic factor since it has been associated with both blood viscosity [39] and NGT 1 hhigh and IGT dysglycemic conditions [42], and it precedes development of type 2 diabetes [43]. We found that subjects with NGT $1 \mathrm{~h}$-high and IGT have increased fibrinogen levels as compared with NGT individuals with 1-h post-load plasma $<155 \mathrm{mg} / \mathrm{dl}$. Elevated levels of fibrinogen are not only a marker of systemic inflammation but have also a role in increasing blood viscosity. The link between elevated 1 -h post-load plasma and subclinical inflammation is probably represented by hyperglycemia that induces oxidative and inflammatory stress, and this effect is more marked in individuals with impaired glucose homeostasis.

Increased lipoproteins concentration may be another shared mechanism linking blood viscosity [3, 39] and elevated 1-h post-challenge plasma glucose [33]. Low HDL levels have been associated with an elevated blood viscosity [3]. According to prior studies [33], we found that subjects with NGT 1 h-high and IGT exhibit a reduction of HDL levels as compared with NGT individuals with 1-h post-load plasma glucose $<155 \mathrm{mg} / \mathrm{dl}$, which was inversely related to whole blood viscosity. It has been suggested that HDL may counteract the aggregation of erythrocytes induced by LDL, thus leading to a decrease in blood viscosity [3].

The results of this study which provide evidence sustaining the link between post-load hyperglycemia and elevated whole blood viscosity may have clinical implications. It has been shown that individuals with 1 -h postchallenge plasma glucose $>155 \mathrm{mg} / \mathrm{dl}$ are characterized by a worse cardiovascular risk profile [32, 33] associated with subclinical organ damage such as carotid 
atherosclerosis [35], vascular stiffness [36], and left ventricular hypertrophy [37], all independent predictors of cardiovascular events. 1-h plasma glucose levels have been found to be predictive of the risk of myocardial infarction and coronary heart disease [44] in subjects affected by type 2 diabetes and total mortality in nondiabetic population [45]. Elevated blood viscosity may represent one of the physio-pathologic mechanisms underlying the link of 1-h hyperglycemia to both type 2 diabetes [20-25, 28-30] and cardiovascular diseases [7-15, 35-37, 44, 45]. Since IGT and IFG have already been recognised as dysglycemic conditions which require specific attention to halt the progression toward type 2 diabetes and decrease the associated cardiovascular risk, employing the 1-h OGTT plasma glucose criterion to screen NGT individuals may be useful to identify a subgroup that would otherwise be regarded as normal who may benefit from life style modifications and/or pharmacologic intervention in order to avoid or slow adverse clinical outcomes.

Strengths of our study are represented by the large sample size comprising men and women, the demographically homogeneous group of White adults, an extended clinical characterization with anthropometric and metabolic data collected according to a standardized protocol that allowed us to adjust for multiple confounders, the centralization of laboratory analyses, the assay of hormones and metabolites in fresh, rather than in stored, blood samples thus preventing possible problem of degradation, the exclusion of confounding chronic disorders potentially affecting both hemoglobin concentration and inflammatory biomarkers, the exclusion of subjects treated with corticosteroids, antiplatelet, anticoagulant, lipid-lowering and hypoglycemic agents.

Nevertheless, some limitations should be taken into account. First, blood viscosity has not been measured directly. However, we estimated blood viscosity in study participants using an equation that has been previously validated [39]. A second limitation is that additional blood parameters related to blood viscosity, such as erythrocyte deformability and aggregability were not measured. However, we analyzed hematological measures commonly used in clinical practice; moreover it should be noted that the size of the study cohort should counterbalance the limited precision of our measures. Additionally, participants underwent a single $75 \mathrm{~g}$ OGTT to assess glucose tolerance, and therefore, it is possible that some subjects might have been misclassified. Nevertheless, in consideration of the large sample size, we believe that the misclassification might have occurred only in a few subjects. Moreover, all variables, including hematocrit, hemoglobin and total protein concentrations were measured once. This approach is commonly used in clinical research, however intra-individual variability in laboratory variables cannot be taken into account. Furthermore, the described analyses were performed on data from subjects deemed at risk of type 2 diabetes and cardiovascular disease collected in an university hospital. Although this may be considered as a limitation of the study, it supports the clinical application of the 1-h OGTT criterion in selected risk populations to identify the individuals who may mostly benefit of intensive intervention program. Additionally, all participants were Whites, and our results should not be applied to other ethnic populations due to differences in socio-demographic, lifestyle, and anthropometric features. Finally, the cross-sectional design of the study reflects only an association of 1-h post-load plasma glucose with whole blood viscosity, and precludes us from discerning cause and effect using this design, nonetheless it provides some pathophysiological clues to support the use of the 1-h OGTT plasma glucose value as additional diagnostic criterion to recognize individuals with an increased risk to develop diabetes. Therefore, our findings need to be confirmed by future prospective studies and should presently be considered as hypothesis generating.

Acknowledgments This work was supported, in part, by the Foundation for Diabetes Research of the Italian Diabetes Society, through the award of "Fondazione Diabete Ricerca FO.DI.RI.-MSD" scholarships in 2014 and 2015 to Gaia Chiara Mannino.

Author contributions M.A.M, T.V.F: researched data, reviewed and edited the manuscript; F.A, A.S: contributed to research data; G.C.M, M.P: reviewed the manuscript; F.P: contributed to the discussion and reviewed the manuscript; G.S. designed the study, analysed the data and wrote the manuscript.

\section{Compliances with ethical standards}

Conflict of interest The authors declare that they have no conflict of interest.

Ethical standard All procedures performed in this study were in accordance with the ethical standards and all participants gave their informed consent in writing prior to inclusion in the study.

Human and animal rights All procedures followed were in accordance with the ethical standards of the responsible committee on human experimentation (Comitato Etico Azienda Ospedaliera "Mater Domini", Italy) and with the Helsinki Declaration of 1975, as revised in 2008 .

Informed consent Informed consent was obtained from all patients for being included in the study.

\section{References}

1. Ciuffetti G, Schillaci G, Lombardini R, Pirro M, Vaudo G, Mannarino E (2005) Prognostic impact of low-shear whole blood viscosity in hypertensive men. Eur J Clin Invest 35:93-98

2. Rillaerts E, van Gaal L, Xiang DZ, Vansant G, De Leeuw I (1989) Blood viscosity in human obesity: relation to glucose tolerance and insulin status. Int J Obes 13:739-745

3. Sloop GD, Garber DW (1997) The effects of low-density lipoprotein and high-density lipoprotein on blood viscosity 
correlate with their association with risk of atherosclerosis in humans. Clin Sci 92:473-479

4. Ernst E (1995) Haemorheological consequences of chronic cigarette smoking. J Cardiovasc Risk 2:435-439

5. Letcher RL, Chien S, Pickering TG, Laragh JH (1983) Elevated blood viscosity in patients with borderline essential hypertension. Hypertension 5:757-762

6. Irace C, Carallo C, Scavelli F, De Franceschi MS, Esposito T, Gnasso A (2014) Blood viscosity in subjects with normoglycemia and prediabetes. Diabetes Care 37:488-492

7. Devereux RB, Drayer JIM, Chien S et al (1984) Whole blood viscosity as a determinant of cardiac hypertrophy in systemic hypertension. Am J Cardiol 54:592-595

8. Zannad F, Voisin P, Brunotte F, Bruntz JF, Stoltz JF, Gilgenkrantz JM (1988) Haemorheological abnormalities in arterial hypertension and their relation to cardiac hypertrophy. J Hypertens 6:293-297

9. Lee AJ, Mowbray PI, Lowe GD, Rumley A, Fowkes FG, Allan PL (1998) Blood viscosity and elevated carotid intima-media thickness in men and women: the Edinburgh Artery study. Circulation 97:1467-1473

10. Zhao HY, Li J, Xu M et al (2015) Elevated whole blood viscosity is associated with insulin resistance and non-alcoholic fatty liver. Clin Endocrinol 83:806-811

11. Tripolino C, Irace C, Carallo C et al (2016) Association between blood viscosity and common carotid artery elasticity. Clin Hemorheol Microcirc 62:55-62

12. Tohgi H, Yamanouchi H, Murakami M, Kameyama M (1978) Importance of the hematocrit as a risk factor in cerebral infarction. Stroke 9:369-374

13. Neumann FJ, Katus HA, Hoberg E (1991) Increased plasma viscosity and erythrocyte aggregation: indicators of an unfavourable clinical outcome in patients with unstable angina pectoris. Br Heart J 66:425-430

14. Yarnell JWG, Baker IA, Sweetnam PM et al (1991) Fibrinogen, viscosity, and white blood cell count are major risk factors for ischemic heart disease. The Caerphilly and Speedwell collaborative heart disease studies. Circulation 83:836-844

15. Lowe G, Lee A, Rumley A, Price J, Fowkes F (1997) Blood viscosity and risk of cardiovascular events: the Edinburgh Artery study. Br J Haematol 96:168-173

16. Høieggen A, Fossum E, Moan A, Enger E, Kjeldsen SE (1998) Whole-blood viscosity and the insulin-resistance syndrome. J Hypertens 16:203-210

17. Nordby G, Moan A, Kjeldsen SE, Os I (1995) Relationship between hemorheological factors and insulin sensitivity in normotensive and hypertensive premenopausal women. Am J Hypertens 8:439-444

18. Catalano C, Muscelli E, Natali A et al (1997) Reciprocal association between insulin sensitivity and the haematocrit in man. Eur J Clin Invest 27:634-637

19. Facchini FS, Carantoni M, Jeppesen J, Reaven GM (1998) Hematocrit and hemoglobin are independently related to insulin resistance and compensatory hyperinsulinemia in healthy, nonobese men and women. Metabolism 47:831-835

20. Hanley AJ, Retnakaran R, Qi Y et al (2009) Association of hematological parameters with insulin resistance and beta-cell dysfunction in nondiabetic subjects. J Clin Endocrinol Metab 94:3824-3832

21. Medalie JH, Papier CM, Goldbourt U, Herman JB (1975) Major factors in the development of diabetes mellitus in 10,000 men. Arch Intern Med 135:811-817

22. Wannamethee SG, Perry IJ, Shaper AG (1996) Hematocrit and risk of NIDDM. Diabetes 45:576-579

23. Nakanishi N, Suzuki K, Tatara K (2004) Haematocrit and risk of development of type 2 diabetes mellitus in middle-aged Japanese men. Diabet Med 21:476-482
24. Tulloch-ReidMK Hanson RL, Saremi A, Looker HC, Williams DE, Krakoff J, Knowler WC (2004) Hematocrit and the incidence of type 2 diabetes in the Pima Indians. Diabetes Care 27:22452246

25. Tamariz LJ, Young JH, Pankow JS et al (2008) Blood viscosity and hematocrit as risk factors for type 2 diabetes mellitus: the atherosclerosis risk in communities (ARIC) study. Am J Epidemiol 168:1153-1160

26. Capoğlu I, Unüvar N, Bektaş Y, Yilmaz O, Kaya MD (2002) The effects of high haematocrit levels on glucose metabolism disorders. J Int Med Res 30:433-437

27. Richards RS, Nwose EU (2010) Blood viscosity at different stages of diabetes pathogenesis. Br J Biomed Sci 67(2):67-70

28. Abdul-Ghani MA, Abdul-Ghani T, Ali N, Defronzo RA (2008) One-hour plasma glucose concentration and the metabolic syndrome identify subjects at high risk for future type 2 diabetes. Diabetes Care 31:1650-1655

29. Abdul-Ghani MA, Lyssenko V, Tuomi T, DeFronzo RA, Groop L (2009) Fasting versus postload plasma glucose concentration and the risk for future type 2 diabetes: results from the Botnia study. Diabetes Care 32:281-286

30. Fiorentino TV, Marini MA, Andreozzi F et al (2015) One-hour postload hyperglycemia is a stronger predictor of type 2 diabetes than impaired fasting glucose. J Clin Endocrinol Metab 100:3744-3751

31. Jagannathan R, Sevick MA, Fink D et al (2016) The 1-h post-load glucose level is more effective than $\mathrm{HbA1c}$ for screening dysglycemia. Acta Diabetol 53:543-550

32. Marini MA, Succurro E, Frontoni S et al (2012) Insulin sensitivity, $\beta$-cell function, and incretin effect in individuals with elevated 1-h postload plasma glucose levels. Diabetes Care 35:868-872

33. Andreozzi F, Mannino GC, Perticone M, Perticone F, Sesti G (2017) Elevated 1-h post-load plasma glucose levels in subjects with normal glucose tolerance are associated with a pro-atherogenic lipid profile. Atherosclerosis 256:15-20

34. Fiorentino TV, Andreozzi F, Mannino GC et al (2016) One-hour postload hyperglycemia confers higher risk of hepatic steatosis to HbA1c-defined prediabetic subjects. J Clin Endocrinol Metab 101:4030-4038

35. Succurro E, Marini MA, Arturi F et al (2009) Elevated one-hour post-load plasma glucose levels identifies subjects with normal glucose tolerance but early carotid atherosclerosis. Atherosclerosis 207:245-249

36. Sciacqua A, Maio R, Miceli S et al (2012) Association between one-hour post-load plasma glucose levels and vascular stiffness in essential hypertension. PLoS ONE 7:e44470

37. Sciacqua A, Miceli S, Carullo G et al (2011) One-hour postload plasma glucose levels and left ventricular mass in hypertensive patients. Diabetes Care 34:1406-1411

38. Perticone M, Tassone EJ, Scarpino PE et al (2016) Sympathovagal balance and 1-h postload plasma glucose in normoglucose tolerant hypertensive patients. Acta Diabetol 53:41-47

39. de Simone G, Devereux RB, Chien S, Alderman MH, Atlas SA, Laragh JH (1990) Relation of blood viscosity to demographic and physiologic variables and to cardiovascular risk factors in apparently normal adults. Circulation 81:107-117

40. Matsuda M, De Fronzo RA (1999) Insulin sensitivity indices obtained from oral glucose tolerance testing: comparison with the euglycemic insulin clamp. Diabetes Care 22:1462-1470

41. Manco M, Panunzi S, Macfarlane DP et al (2010) One-hour plasma glucose identifies insulin resistance and beta-cell dysfunction in individuals with normal glucose tolerance: crosssectional data from the relationship between insulin sensitivity and cardiovascular risk (RISC) study. Diabetes Care 33:20902097 
42. Sesti G, Fiorentino TV, Succurro E et al (2014) Elevated 1-hour post-load plasma glucose levels in subjects with normal glucose tolerance are associated with unfavorable inflammatory profile. Acta Diabetol 51:927-932

43. Duncan BB, Schmidt MI, Pankow JS et al (2003) Low-grade systemic inflammation and the development of type 2 diabetes. The arteriosclerosis risk in communities study. Diabetes 52: 1799-1805

44. Cavalot F, Petrelli A, Traversa M et al (2006) Postprandial blood glucose is a stronger predictor of cardiovascular events than fasting blood glucose in type 2 diabetes mellitus, particularly in women: lessons from the San Luigi Gonzaga diabetes study. J Clin Endocrinol Metab 91:813-819

45. Bergman M, Chetrit A, Roth J, Dankner R (2016) One-hour postload plasma glucose level during the OGTT predicts mortality: observations from the Israel study of glucose intolerance, obesity and hypertension. Diabet Med 33:1060-1066 